\title{
Physically based distributed hydrological modelling of the Upper Jordan catchment and investigation of effective model equations
}

\author{
H. Kunstmann ${ }^{1}$, A. Heckl ${ }^{1}$, and A. Rimmer ${ }^{2}$ \\ ${ }^{1}$ Forschungszentrum Karlsruhe, Institute for Meteorology and Climate Research (IMK-IFU), Kreuzeckbahnstraße 19, \\ 82467 Garmisch-Partenkirchen, Germany \\ ${ }^{2}$ Kinneret Limnological Laboratory, PO Box 447, Migdal 14950, Israel
}

Received: 23 January 2006 - Revised: 22 May 2006 - Accepted: 3 July 2006 - Published: 26 September 2006

\begin{abstract}
Sufficient freshwater availability in the water scarce environment of the Upper Jordan Catchment (UJC) is a central prerequisite for peaceful agricultural and industrial development. Hydrological modelling is required to understand terrestrial water balance and to provide scientifically sound estimates on water availability.

This article aims at two related objectives: First the water balance of the UJC, a hydrogeologically complex catchment located at the borders of Israel, Syria and the Lebanon, is investigated. It is for the first time that a physically based model is set up for this region that accounts both for the entire terrestrial water balance and in particular for the groundwater-surface water interaction. It is shown that the model is able to describe observed river discharges satisfactorily.

Secondly, it is investigated if observed and simulated runoff components can be explained by simple lumped approaches based on 1) linear filter theory and 2) neural networks and what the number of degrees of freedom for the runoff components is. It is exemplary shown for the Ayun subcatchment of the UJC that the simulated river discharge, the direct runoff component and the interflow runoff component as modelled by the physically based distributed hydrological model WaSiM can be described by simple effective equations with only 3 to 5 degrees of freedom. Application of simple lumped approaches to observed river discharge values showed much weaker performance.
\end{abstract}

\section{Introduction}

Physically or semi-physically based models calculate the water balance components of the terrestrial part of the hydrological cycle and usually require a large number of parameters (land surface, vegetation and soil properties e.g.) that are difficult to obtain. As a consequence, even physically based models usually are tuned or calibrated by estimating the parameters that are not known a-priori and consequently have a high number of degrees of freedom. In most cases, only river discharge values are used for model performance evaluation. The central question arises, what the number of degree of freedom for the runoff components is, and whether the complicated set of complex water balance equations finally leading to the runoff components can be replaced by effective expressions of much simpler nature.

Physically based models have the advantage that they calculate the complete terrestrial water balance, i.e. the processes of land-surface flow aggregation, infiltration in the unsaturated zone, evapotranspiration by open water bodies, plants or bare soil, up to the consideration of groundwater recharge, groundwater flow and its re-infiltration in surface waters. Due to the solution of mostly physically based equations, a high prognostic capability, e.g. under climate change or land use change conditions, is assumed for these kind of models. The disadvantages, on the other hand, clearly are 1) the computational demand, and 2) the high input data demand on a gridded basis. Detailed information of spatial distribution of soils, vegetation and land surface properties is needed, which is often not available, in particular in areas of weak infrastructure. Due to the high CPU demand, calibration of physically or semi-physically based models can still be a tremendous effort.

The solution of a complicated and coupled set of equations finally leads to the derivation of water balance variables, and in particular river discharge, which is often the only variable of interest and the only variable that can directly be compared to observations.

Correspondence to: H. Kunstmann

(harald.kunstmann@imk.fzk.de)

Published by Copernicus GmbH on behalf of the European Geosciences Union. 


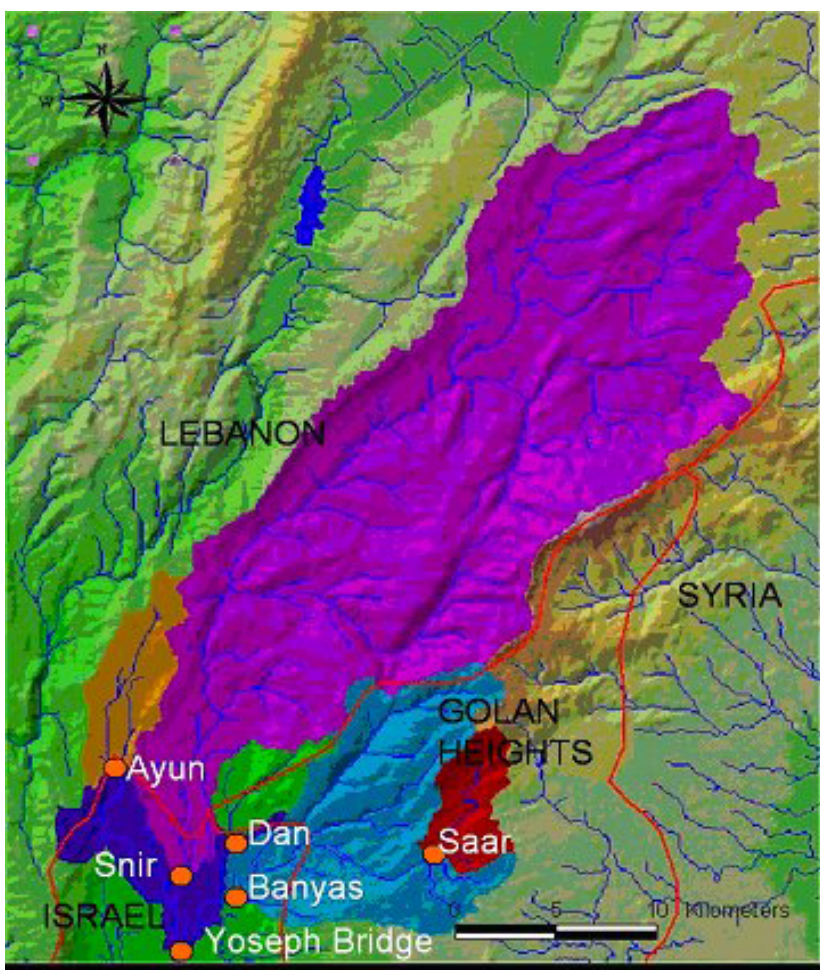

Fig. 1. Location of subcatchments and respective gauges of Upper Jordan catchment.

\section{Distributed physically based hydrological modelling of the Upper Jordan catchment (UJC)}

The UJC has an extension of $855 \mathrm{~km}^{2}$, which is only a small part of the entire Jordan catchment $\left(18200 \mathrm{~km}^{2}\right)$. In spite of the small size of the UJC, the catchment is of great importance because it provides the majority of the whole Jordan's discharge and 1/3rd of the freshwater resources of Israel. The UJC is located within the border of Lebanon, Syria, Israel and the Golan Heights. The area is divided in the subcatchments of the three spring-fed tributaries Snir in the West, Dan in the centre and Banias in the East. Their springs are located on the western and southern slopes at the base of the Mount Hermon, a massive anticlinal feature at the eastern part of the area with a maximal elevation of 2814 ma.s.l. On the upper slopes of Mount Hermon exposed Jurassic carbonate rocks build the recharge area of a widespread regional groundwater aquifer with characteristic karstic attributes and a thickness of several hundred meters. The area is included in the Mediterranean climate region and receives an annual precipitation from about $750 \mathrm{~mm}$ in the valleys up to $1500 \mathrm{~mm}$ at the top of Mount Hermon. Rainfall is limited to the period from end of October to the beginning of May with a maximum in January. Starting from an elevation of $2000 \mathrm{~m}$ a.s.l., precipitation often falls as snow. Its accumulations are able to persist till summer and serve as an important reservoir for the dry months. The mean annual temperature is $13-18^{\circ} \mathrm{C}$ with an accordant decrease with the elevation.
The distributed hydrological model WaSiM (Schulla and Jasper, 2001) was applied in $90 \times 90 \mathrm{~m}^{2}$ horizontal resolution to perform the hydrological simulations of the UJC. WaSiM uses physically based algorithms for the majority of the process descriptions, like infiltration description according to Green and Ampt (1911), estimation of saturation time according to Peschke (1987) and solution of the Richards equation (Richards, 1931; Phillip, 1969) for the description of the soil water fluxes in the unsaturated zone (Jasper et al., 2002). The dependence of the suction head and the hydraulic conductivity on soil moisture content is parameterized according to van Genuchten (1976). Interflow is calculated in defined soil layers, depending on suction, drainable water content, hydraulic conductivity, and gradient. Surface runoff is routed to the subbasin outlet using a subdivision of the basin into flow time zones. For considering retention, a single linear storage approach is applied to the surface runoff in the last flow time zone. Translation and retention of interflow is treated accordingly. Potential evapotranspiration is soil- and vegetation specifically calculated according to Penman-Monteith (Monteith, 1975; Brutsaert, 1982); real evapotranspiration is obtained by respective reduction of potential evapotranspiration according to actual soil moisture content. Interception is accounted for by a bucket approach. Snow accumulation and snowmelt is performed according to Anderson (1973) and Braun (1985). Surface runoff is calculated for each grid cell as sum of infiltration excess and snow melt along the topographic gradient towards the next river. It is assumed that saturated hydraulic conductivity decreases (dependent on soil texture) with depth according to a recession constant. Discharge routing is performed by a kinematic wave approach using different flow velocities for different water levels in the channel. After the translation of the wave a single linear storage is applied to the routed discharge considering diffusion and retention (Schulla and Jasper, 2001). We applied WaSiM with an integrated 2D groundwater flow model, which couples dynamically to the unsaturated zone. The upper-most (and in this study single) aquifer is assumed to be unconfined. Infiltration from rivers into groundwater and exfiltration (which is the base flow) from groundwater into rivers is calculated using the hydraulic gradient and the colmation (in- and exfiltration resistance) at the river bed. WaSiM does not solve the heat flux balance in the soil/subsurface and therefore it is not able to account for frozen soil effects.

The river courses were derived based on a digital elevation model with $90 \times 90 \mathrm{~m}^{2}$ resolution (based on SRTM satellite mission digital elevation data) and additional data on mean runoff. River discharge information of six gauges (Ayun, Snir, Dan, Banyas, Saar, and the Jordan at Yoseph's bridge) are available for this study. The corresponding subcatchments are shown in Fig. 1.

Gridded soil data was compiled from Israelian national data sets (provided by the Kinneret Limnological Laboratory) and from FAO data for the Syrian and Lebanese 


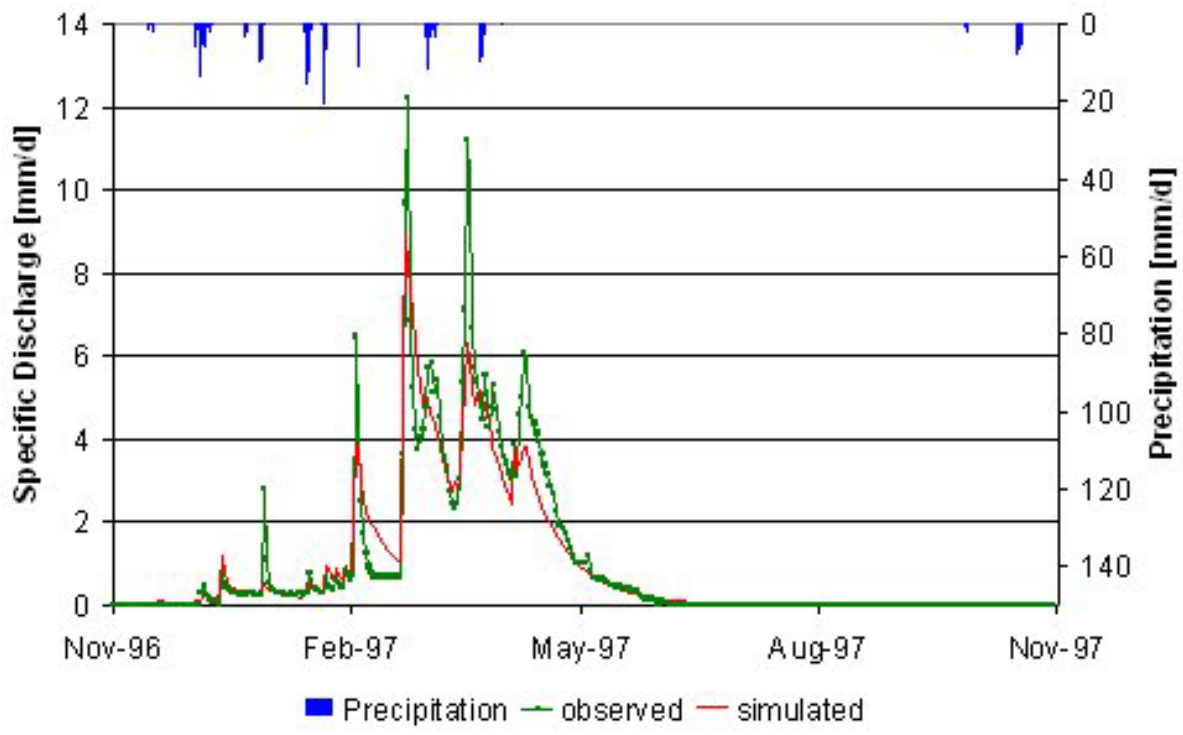

Fig. 2. Modeled and observed discharge Saar subcatchment for 1996-1997.

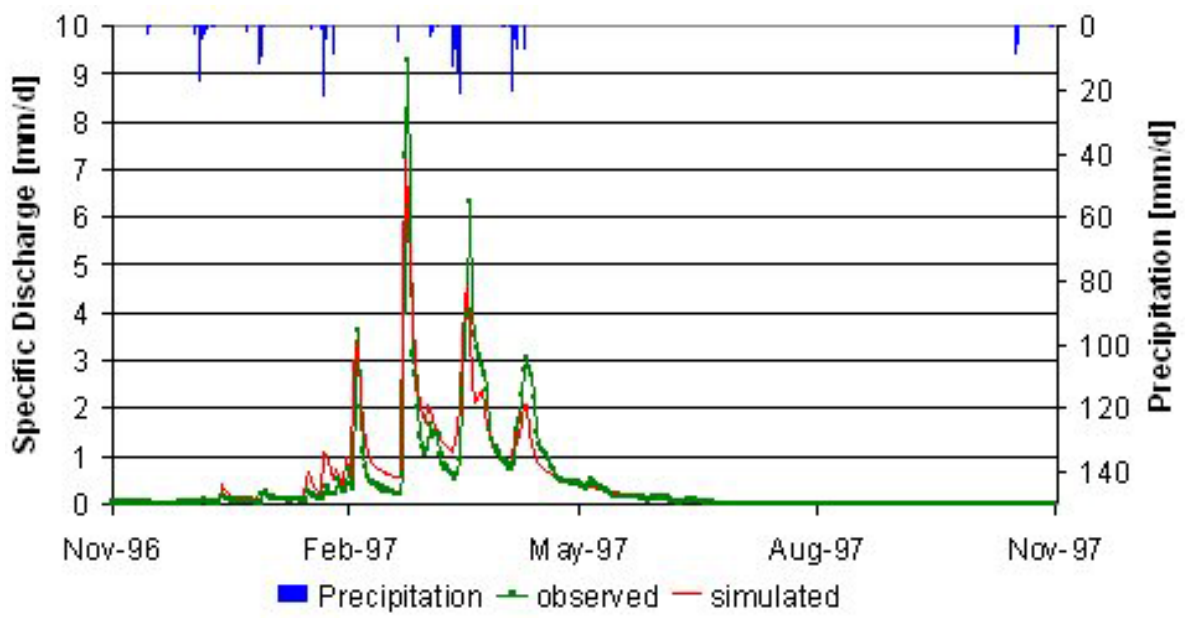

Fig. 3. Modeled and observed discharge Ayun subcatchment for 1996-1997.

part of the UJC. Gridded land use information was again obtained from Israelian national data sets and derived from MODIS satellite information for Syrian and Lebanon part of the UJC. We distinguished between 6 different soil textures and 8 different land use types within the catchment.

The borders of the groundwater aquifer are basically unknown, and therefore, for reasons of simplicity, the boundary of the uppermost unconfined aquifer was considered to be identical with the boundary of the surface water catchment. Outflow of groundwater at parts of the eastern boundary along the Hermon mountain and additionally at the northeastern edge of the Snir subcatchment, were estimated from Gur et al. (2003) and accordingly implemented in the model setup. Moreover, Dan-, El-Wazani, Hazbani and Banyas springs are accounted for by defining constant groundwa- ter heads at the respective locations. It is emphasized that the hydrological model is not able to account for the karstic environment and corresponding preferential flowpaths. Water flow is rather approximated assuming porous conditions. The model therefore represents a substitutional porous media model whose parameters must be interpreted as effective parameters approximating the karstic environment on subcatchment scale.

Hydrological modelling of the UJC is additionally hampered by the limited availability of daily meteorological station data. While in the Israelian part of the catchment, only 2 precipitation stations but no climatological stations are available, no daily station data in the Syrian and Lebanese part of the catchment are accessible. 6 Israelian precipitation stations and 2 climatological stations outside of the catch- 


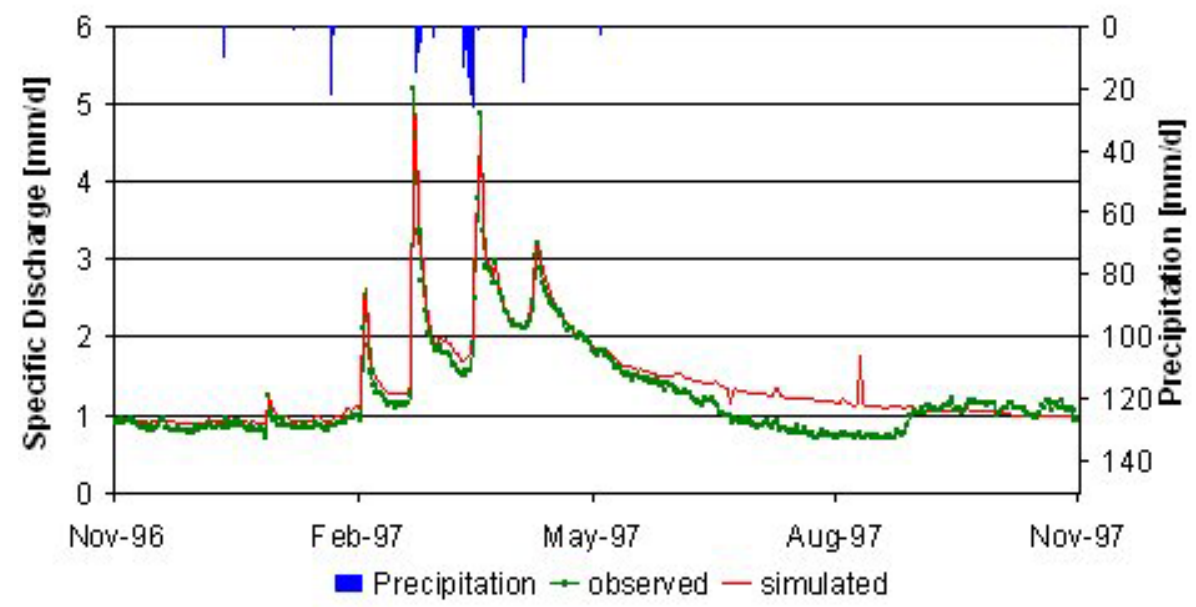

Fig. 4. Modeled and observed discharge at Yoseph Bridge (Jordan river) for 1996-1997.

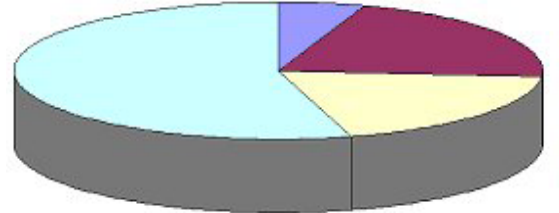

$\square$ Base flow $5 \%$

口Interflow $21 \%$

$\square$ Direct runoff $19 \%$

$\square$ Evapotranspiration $55 \%$

Fig. 5. Water balance of subcatchment Snir for the years November 1995-October 1999.

ment are additionally applied. In Syria, Lebanon and Jordan, 9 precipitation stations as well as 6 climatological stations outside the catchment up to a maximum distance of $80 \mathrm{~km}$ to the catchment were supplementary utilised. Gridded daily meteorological fields were obtained by a combination of inverse distance weighting and height dependent regression of stations values.

Figures 2, 3 and 4 show a comparison between modeled and observed discharges for the subcatchments Saar, Ayun and the Jordan at Yoseph bridge. The simulated discharges correspond well to observed values, albeit reduced quality of simulated low flow in case of Saar and Ayun subcatchments is due to limitations of the coupled groundwater model. Overestimation of simulated discharge at Yoseph bridge is due to the fact that water consumption and technically bypassed freshwater is not yet accounted for in the current hydrological model setup.

Altogether it is concluded that the hydrological model is able to describe the water balance in the UJC satisfactorily at the above mentioned constraints. Preliminary water balance analysis of the years 1995-1999 (Fig. 5) indicates that around $55 \%$ of mean precipitation is evapotranspirated and around $19 \%$ is transformed to direct runoff. Assuming that both interflow $(21 \%)$ and groundwater recharge induced base flow $(5 \%)$ contribute to river low flow means that $26 \%$ of to-

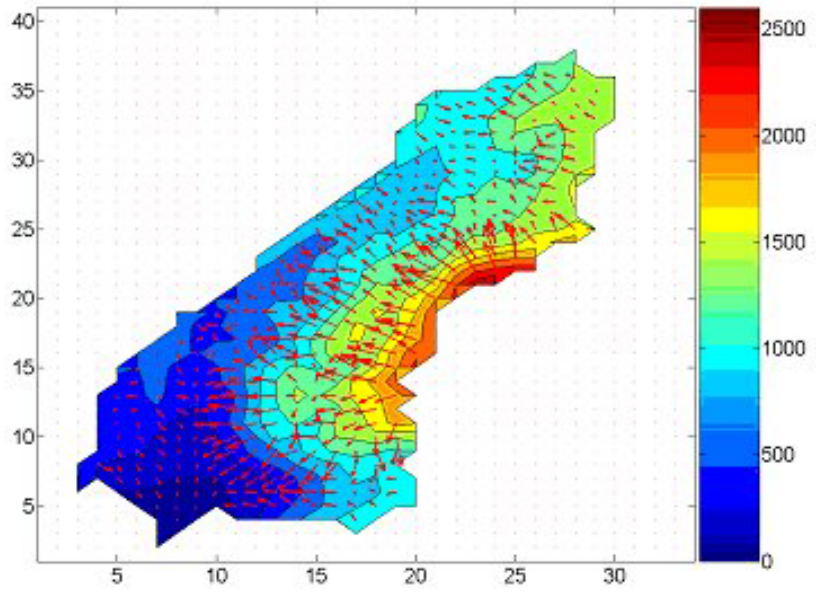

Fig. 6. Average groundwater flow directions and head distribution (in $\mathrm{m}$ a.s.1.) of the first unconfined aquifer in the UJC. Axes indicate distances in $[\mathrm{km}]$.

tal precipitation is transformed to total river base flow. This is in agreement with recent estimates based on baseflow separation techniques (Alon Rimmer, 2006, personal communication). Figure 6 illustrates modelled mean groundwater head distribution and derived flow directions and intensities. Main groundwater flow is directed from the hilly/mountainous areas towards the river valleys.

The advantage of the physical based distributed hydrological model clearly is the information on all terrestrial water balance variables, from evapotranspiration, surface runoff, infiltration till groundwater flow and surface water/groundwater interactions. However, if only the proper description of selected variables like surface runoff is of interest, the questions arises, whether much simpler model equations could be applied. For a more detailed discussion of the advantages and disadvantages between complex physically 
Table 1. Analysis of performance of effective model equations substituting WaSiM calculated river discharge at gauge Ayun (ANN: artificial neural network with sigmoidal neuron transfer function).

\begin{tabular}{lccc}
\hline & Linear Filter & ANN with 1 hidden layer & ANN with2 hidden layers \\
\hline Degrees of freedom & 3 & 5 & 9 \\
$N S_{\text {Calib }}$ & 0.805 & 0.874 & 0.941 \\
$N S_{\text {Valid }}$ & 0.853 & 0.831 & 0.832 \\
$E V_{\text {Calib }}$ & 0.820 & 0.877 & 0.942 \\
$E V_{\text {Valid }}$ & 0.854 & 0.834 & 0.837 \\
\hline
\end{tabular}

Table 2. Analysis of performance of effective model equations substituting WaSiM calculated direct runoff for subcatchment Ayun. *The weak performance in the validation phase in case of "ANN with 2 hidden layers" arises from overestimation of peak flows in March 1997 by this specific approach. An extension of the calibration period is able to overcome this shortcoming.

\begin{tabular}{lccc}
\hline & Linear Filter & ANN with 1 hidden layer & ANN with 2 hidden layers \\
\hline Degrees of freedom & 3 & 5 & 9 \\
$N S_{\text {Calib }}$ & 0.870 & 0.913 & 0.943 \\
$N S_{\text {Valid }}$ & 0.871 & 0.906 & $-580^{*}$ \\
$E V_{\text {Calib }}$ & 0.879 & 0.913 & 0.943 \\
$E V_{\text {Valid }}$ & 0.871 & 0.907 & $-178^{*}$ \\
\hline
\end{tabular}

based and simple conceptual models and in particular of the problem of proper parameterisation of hydrological models, it is referred to Beven (2001).

Focus of this study are the questions 1) do simple effective equations for the output of the physically based hydrological model exist, and 2) what is the respective number of degrees of freedom determining the runoff components?

\section{Simple hydrology: investigation of effective model equations for runoff components in the Upper Jordan catchment}

The most simple approach for the description of runoff $q(t)$ $(q(t)$ representing either river discharge, direct runoff, interflow or baseflow) is the assumption that $q(t)$ at a certain time $t$ is a linear function of the precipitation $p(t)$ and the runoff $q(t-\Delta t)$ at the previous time step $t-\Delta t$ :

While Eq. (1) is a linear filter model (LFM) of runoff $q(t)$ with exogenous input $p(t)$ (which is the areal averaged precipitation in the respective subcatchment), it can be viewed as an efficient model equation in case $q(t-\Delta t), q(t-2 \Delta t)$, ... are all obtained by Eq. (1) itself. This means, $q(t)$ is iteratively traced back to initial runoff $q(t=0)$ and fully determined by precipitation $p(t)$ at all times:

$q_{L F M}(t)=q(q(t=0), p(t)) \Leftrightarrow q_{L F M}(t)=a+b \cdot p(t)+c \cdot q_{L F M}(t-\Delta t)$

Alternatively to the above mentioned simple linear approach, the performance of artificial neural networks (ANN) is inves- tigated. For further details of ANN, it is referred to Haykin (1999) and Herz et al. (1991). In this application, feedforward neural network and sigmoidal neural transfer functions are applied. The response $q(t)$ of the ANN to previous runoff $q(t-\Delta t)$ and precipitation $p(t)$ as exogenous input, then finally reduces to

$q(t)=a+\sum_{i=1}^{N H L} \frac{b_{i}}{1+e^{c_{i}+d_{i} \cdot q(t-\Delta t)+e_{i} \cdot p(t)}}$

where $N H L$ is the number of hidden layers in the ANN. The tuneable parameters $a, b_{i}, c_{i}, d_{i}, e_{i}$ are obtained iteratively by Levenberg-Marquardt non-linear parameter estimation (e.g. Marquardt, 1963; Press et al., 1992) such that the root mean square error RMSE is minimised:

$R M S E=\sqrt{\frac{1}{N} \sum_{i=1}^{N}\left(q_{\mathrm{ANN}}\left(t_{i}\right)-q_{W A S I M}\left(t_{i}\right)\right)^{2}} \rightarrow \min$

Similar to the linear approach of Eq. (2), an effective model equation is approximated by:

$q(t)=q(q(t=0), p(t)) \Leftrightarrow q_{\mathrm{ANN}}(t)=a+\sum_{i=1}^{N H L} \frac{b_{i}}{1+e^{c_{i}+d_{i} \cdot q_{\mathrm{ANN}}(t-\Delta t)+e_{i} \cdot p(t)}}$

The effective model Eqs. (2) and (5) are used to reproduce the WaSiM-modelled output of a) river discharge at subcatchment outlet, 2) the direct runoff flow component, and 
Table 3. Analysis of performance of effective model equations substituting WaSiM calculated interflow for subcatchment Ayun.

\begin{tabular}{lccc}
\hline & Linear Filter & ANN with 1 hidden layer & ANN with 2 hidden layers \\
\hline Degrees of freedom & 3 & 5 & 9 \\
$N S_{\text {Calib }}$ & 0.825 & 0.794 & 0.701 \\
$N S_{\text {Valid }}$ & 0.643 & 0.657 & 0.500 \\
$E V_{\text {Calib }}$ & 0.826 & 0.830 & 0.723 \\
$E V_{\text {Valid }}$ & 0.763 & 0.737 & 0.747 \\
\hline
\end{tabular}

Table 4. Analysis of performance of effective model equations reproducing observed river discharge at gauge Ayun.

\begin{tabular}{lccc}
\hline & Linear Filter & ANN with 1 hidden layer & ANN with 2 hidden layers \\
\hline Degrees of freedom & 2 & 5 & 9 \\
$N S_{\text {Calib }}$ & 0.47 & -6.47 & 0.29 \\
$N S_{\text {Valid }}$ & 0.64 & -5.9 & -0.46 \\
$E V_{\text {Calib }}$ & 0.47 & 0.15 & 0.40 \\
$E V_{\text {Valid }}$ & 0.64 & 0.25 & -0.07 \\
\hline
\end{tabular}

3) the interflow component. The performance of the simplehydrology approach in reproducing/explaining the WaSiMsimulated runoff output is analysed by computation of respective Nash-Sutcliff (NS) values

$$
N S=1-\frac{\sum_{i=1}^{N}\left(q_{\text {simple }}\left(t_{i}\right)-q_{W \operatorname{ASIM}}\left(t_{i}\right)\right)^{2}}{\sum_{i=1}^{N} q_{W \operatorname{ASIM}}\left(t_{i}\right)^{2}-\frac{1}{N}\left(\sum_{i=1}^{N} q_{W \operatorname{ASIM}}\left(t_{i}\right)\right)^{2}}
$$

and explained variances $(E V)$

$$
E V=1-\frac{\sum_{i=1}^{N}\left(q_{\text {simple }}\left(t_{i}\right)-q_{\text {WASIM }}\left(t_{i}\right)\right)^{2}-\frac{1}{N}\left(\sum_{i=1}^{N}\left(q_{\text {simple }}\left(t_{i}\right)-q_{\text {WASIM }}\left(t_{i}\right)\right)\right)^{2}}{\sum_{i=1}^{N} q_{\text {WASIM }}\left(t_{i}\right)^{2}-\frac{1}{N}\left(\sum_{i=1}^{N} q_{W A S I M}\left(t_{i}\right)\right)^{2}}
$$

for both the calibration (i.e. training) phase (November 1995-October 1996 in this application) and the validation period (November 1996-October 1997). $N$ is the number of data points and is equal to 365 for both the training and the validation phase.

Table 1 shows the performance criteria of the effective model equations for routed river discharge. Beside the linear approach of Eq. (2), the ANN approach is applied using a) 1 hidden layer and b) 2 hidden layers. All performance criteria are above 0.80 , indicating the ability of the effective model equation to reproduce the WaSiM-modelled river discharge satisfactorily, however with a much smaller number of degrees of freedom. It becomes obvious that the result of the complicated set of equations in WASIM yielding the routed river discharge can be substituted in simple, albeit unphysical expressions like Eqs. (2) and (5). In case of Eq. (2), three parameters are sufficient to reproduce WaSiM modelled river discharge, in case of Eq. (5) five (ANN-1 hidden layer effective model), respectively 9 (ANN-2 hidden layer effective model), parameters are sufficient.

A comparison between the WaSiM modelled discharge curve and the linear transfer function substitute is shown in Fig. 7; a comparison to the ANN-1 hidden layer substitute is shown in Fig. 8. As the $N S$ and $E V$ values already indicated, the agreement between the two methods is satisfying. Table 2 shows the performance of the three effective models of Eqs. (2) and (5), when applied to the direct runoff, likewise Table 3 for the interflow. While in case of direct surface runoff, the performance criteria are in general slightly higher than for routed river discharge, the values of the performance criteria are lower in case of interflow runoff component, but still remarkable considering the crude lumped approach. The ANN-2 hidden layer model, however, did not provide reasonable results in case of direct interflow reproduction in the validation phase.

Finally, the performance of the above described simple hydrology approaches in reproducing observed rather than WaSiM-simulated river discharge is investigated. Table 4 shows the performance of the simple hydrology approach for reproducing observed discharge at gauge Ayun, both for the calibration and validation period. The performance for reproducing observed discharge is much weaker than in case of reproducing WaSiM-simulated discharge (see Table 1). Particularly, the ANN approach fails in describing satisfactorily observed discharge. Increased number of model parameters (i.e. increased numbers of degrees of freedom) did not 


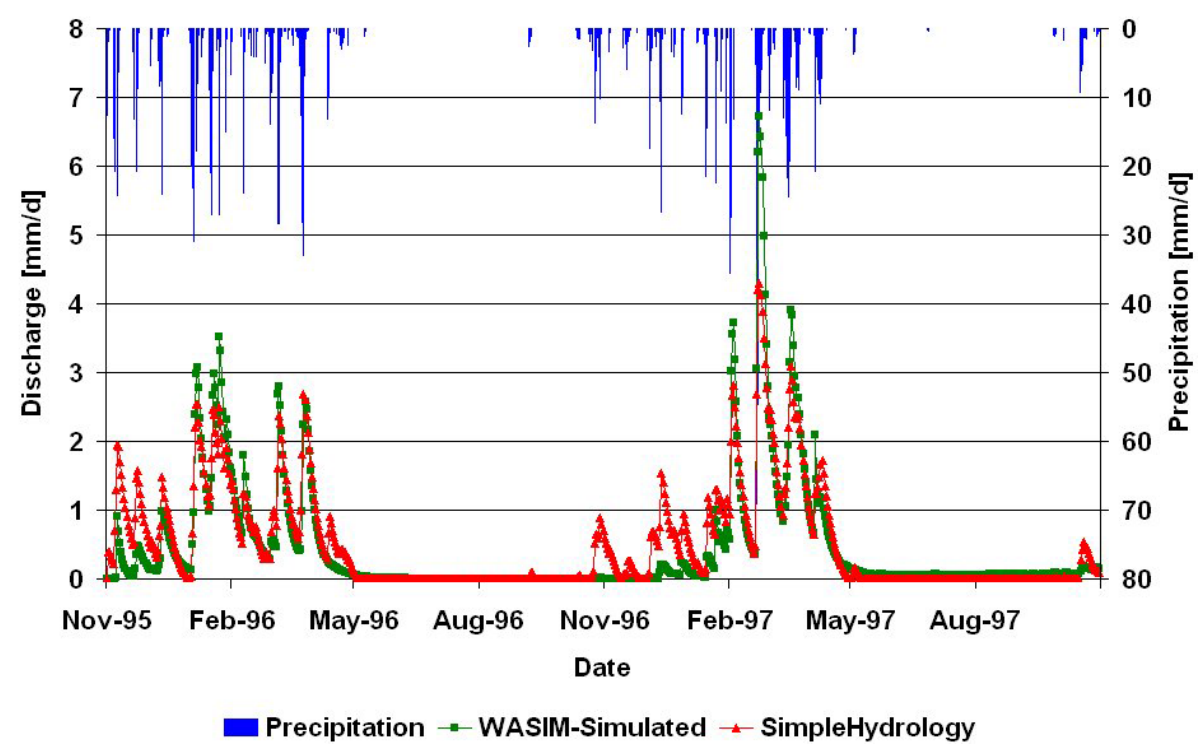

Fig. 7. Comparison between original WaSIM-modeled vs. effective linear function modelled river discharge in [mm/d] for the Ayun catchment. Calibration period November 1995-October 1996, validation period November 1996-October 1997.

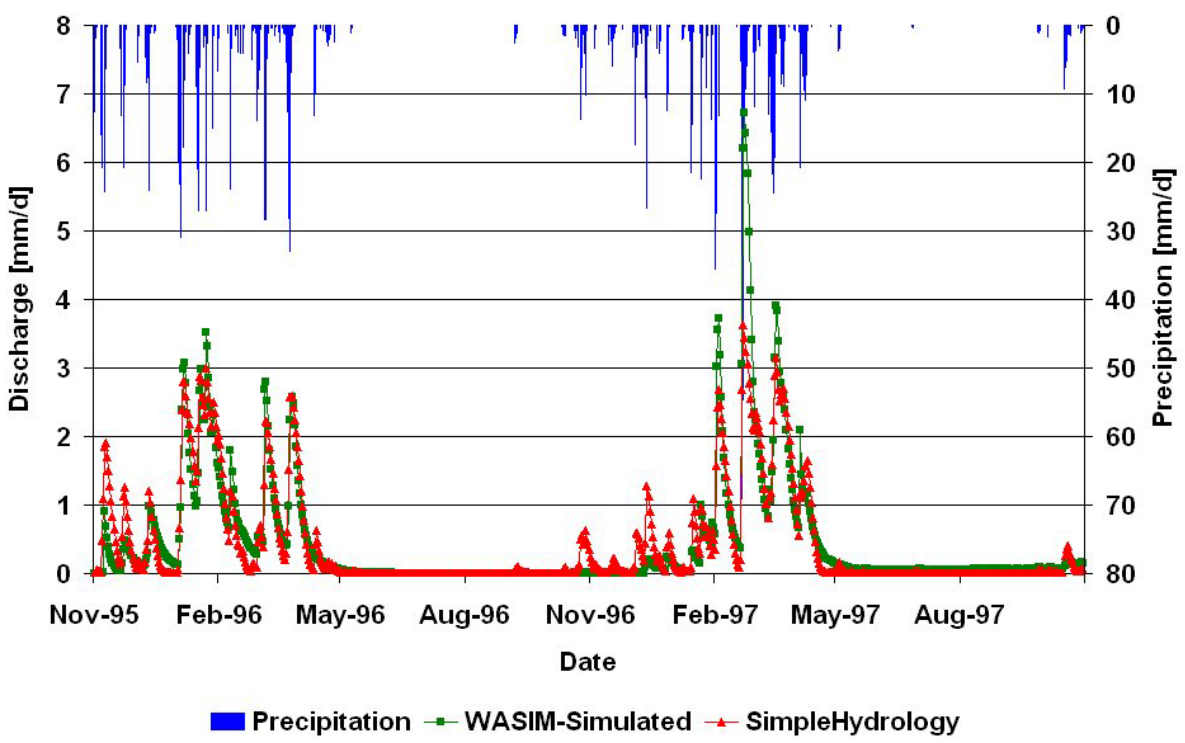

Fig. 8. Comparison between original WaSIM-modeled vs. ANN (one hidden layer)-simple hydrology derived river discharge in [mm/d] for the Ayun catchment. Calibration period November 1995-October 1996, validation period November 1996-October 1997.

improve model performance. Considering the good agreement between observed discharge and WaSiM-simulated discharge (see Figs. 2, 3 4), this result could not be expected in advance. It seems as if simulated discharge reacts much smoother to precipitation than the actual observed discharge and that simulated discharge does not properly reproduce fine scale dynamics. As WaSiM was only calibrated and validated by observed river discharge, these findings indicate the necessity to calibrate and validate by comparison to groundwater table elevations and environmental tracer data which will further narrow parameter solution space. Albeit not shown explicitly in this work, further investigations on the application of linear filter theory and artificial neural network approaches for reproducing WaSiM-modelled evapotranspiration (whereas beside of precipitation additionally information of temperature, radiation and humidity was applied) did also not show satisfying results. This leads to the conclusion that in case of the runoff components (and in this specific case study) the complicated set of equations of the applied physically based hydrological model seem to sum up to an 
effective equation that is determined by precipitation and 3-5 additional parameters only. For other water balances variables, like evapotranspiration, this is not the case.

\section{Summary and conclusions}

The physically based hydrological model WaSiM successfully reproduced observed river discharges for the UJC. A water balance analysis was performed also revealing main groundwater flow directions in the UJC. In future studies, the model will be used for decision support and studies on impact of climate change on terrestrial water balances in the UJC.

Simple lumped approaches based on linear filter theory and artificial neural networks revealed that the simulated runoff components (routed river discharge, direct surface runoff and interflow) can effectively be described by precipitation and a small number ( 3 to 5 ) of adjustable parameters only. It was shown that simulated runoff components can be reproduced more easily than actual observed runoff, in spite of the actual good coincidence between observed and simulated runoff in WaSiM. Application of the methodology to further catchments, other physically based hydrological models and extended calibration/validation periods must be performed to investigate to which extend the findings are model specific and catchment specific.

Acknowledgements. The financial support of the BMBF (Germany Ministry of Education and Science) program "GLOWA-Jordan River" for this work is gratefully acknowledged.

Edited by: R. Barthel, J. Götzinger, G. Hartmann, J. Jagelke, V. Rojanschi, and J. Wolf

Reviewed by: anonymous referees

\section{References}

Anderson, E.: National Weather River Forecast System - Snow Accumulation and Ablation Model, NOAA, Tech. Mem., NWSHydro-17, U.S. Department of Commerce, USA, 1973.

Beven, K.: Rainfall-Runoff Modelling - The Primer, John Wiley \& Sons, England, 2001.

Braun, L. N.: Simulation of snowmelt-runoff in lowland and lower alpine regions of Switzerland, Zürcher Gegraphische Schriften, ETH Zürich, 21, 166pp, 1985.

Brutsaert, W.: Evaporation into the Atmosphere, Kluwer Academic Publishers, Dordrecht, 1982.

Green, W. H. and Ampt, G. A.: Studies on Soil Physics: I. The flow of air and water trough soils, J. Agric. Sci., 4, 1-24, 1911.

Gur, D., Bar-Matthews, M., and Sass, E.: Hydrochemistry of the main Jordan River sources: Dan, Banias, Kezinim springs, north Hula Valley, Israel, Isr. J. Earth Sci, 52, 155-178, 2003.

Haykin, S.: Neural Networks: A Comprehensive Foundation, Second Edition, Macmillan, New York, 1999.

Herz, J., Krough, A., and Palmer, R. G.: Introduction to the Theory of Neural Computation, Addison-Wesley, Reading, MA., 1991.

Marquardt, D.: An algorithm for least-squares estimation of nonlinear parameters, Journal of the Society of Industrial and Applied Mathematics, 11, 431-441, 1963.

Monteith, J. L.: Vegetation and the Atmosphere, Vol. 1: Principles, Academic Press, London, 1975.

Peschke, G.: Soil Moisture and Runoff Components from a Physically Founded Approach, Acta hydrophysica, 31(3/4), 191-205, 1987.

Phillip, J. R.: The theory of infiltration, in: Advances in Hydrosciences, edited by: Chow, V. T., Academic Press, New York, 216-296, 1969.

Press, W., Teukolsky, S., Vetterling, W., and Flannery, B.: Numerical Recipes in C, 2nd edition, Cambridge University Press, Cambridge, 1992.

Richards, L. A.: Capillary Conduction of liquids through porous medium, Physics, 1, 318-333, 1931.

Schulla, J. and Jasper, K.: Model Description WASIM-ETH (Water Balance Simulation Model ETH), ETH-Zurich, Zurich, 2001.

Van Genuchten, M. T.: A Closed Form Equation for Predicting the Hydraulic Conductivity of Unsaturated Soils, Amer. J. Soil Sci., 44(5), 892-898, 1976. 